\section{Strengths, weaknesses, opportunities and threats in higher education: a SWOT analysis of Allama Iqbal Open University Islamabad (Pakistan)}

A SWOT analysis of AIOU

\author{
Khalida Nasreen
}

Education Department, Tribal area of Dera Ghazi Khan, Pakistan and Education Department, AIOU, Islamabad, Pakistan, and

Muhammad Tanveer Afzal

Education Department, AIOU, Islamabad, Pakistan
Received 5 November 2019 Revised 11 January 2020 14 January 2020 4 February 2020

29 February 2020

19 June 2020

1 July 2020

27 July 2020

16 August 2020

9 September 2020

14 September 2020 Accepted 16 September 2020

\begin{abstract}
Purpose - The purpose of the study is to identify the strengths, weaknesses, opportunities and threats in higher education regarding distance learning system in Pakistan.

Design/methodology/approach - A mixed-method research design was used in this study. The population of the study was all the previous students of research work and all the teachers of these students working at MPhil and PhD level in AIOU in Pakistan. Stratified random sampling technique was used in this study. This study used the questionnaire and interview technique to collect data. Data of questionnaire was in numbers and data of interview was narrative. So it was the need of the study that a mixed-method approach, i.e. both quantitative and qualitative techniques should be used in this study.

Findings - The findings of the study show that AIOU has also strengths, weaknesses, opportunities and threats in higher education related to distance education like all the formal and distance universities of Pakistan and World. This study reflected that AIOU is a great blessing for those who cannot acquire their education regularly because of financial/family problems or they are job holders. But this study also described that at higher level students are facing a lot of problems especially there is a delay in research process and provision of no scholarships to students. The teachers have a low salary package than the other public universities of Pakistan and a lot of responsibilities to attend meetings, seminars, conferences and workshops. So they have less time for research work. And AIOU provides them fewer opportunities to go abroad for further studies or to attend conferences/seminars. This study recommended that there should be adopted such policies in AIOU that students could get their study materials, assignments duration, workshops schedule and degrees in time, the teachers of the concerned departments should allow to take more in numbers the students under their supervision, the pay package for the teachers working at MPhil and $\mathrm{PhD}$ level should be raised and the opportunities for the faculty members to go.

Research limitations/implications - This study is limited to analyze the higher education system especially the distance learning system in Pakistan.

Practical implications - This study has indicated the strengths, weaknesses, opportunities and threats in higher education which the AIOU is facing recently and the policymakers can develop plans/strategies to make better the distance learning system especially at higher level in Pakistan. This study can be helpful for the stakeholders who are interested in distance learning system. This study was conducted at higher level in the distance learning system but it can open the ways for the other researchers to conduct research in other disciplines related to distance education, i.e. at matric level,F.A/F.SC,B.Sc programs, Master level and M.Sc programs at AIOU. Social implications - Through this study, it can be acknowledged how the AIOU is providing the opportunity of education to a large number of people in the society who cannot study regularly in the formal
\end{abstract}

(C) Khalida Nasreen and Muhammad Tanveer Afzal. Published by Emerald Publishing Limited. This article is published under the Creative Commons Attribution (CC BY 4.0) licence. Anyone may reproduce, distribute, translate and create derivative works of this article (for both commercial and noncommercial purposes), subject to full attribution to the original publication and authors. The full terms of this licence may be seen at http://creativecommons.org/licences/by/4.0/legalcode

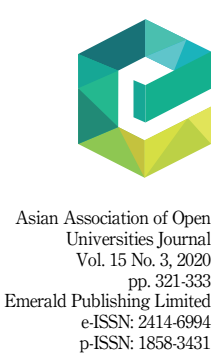

DOI 10.1108/A AOUJ 11-2019-3431 


\section{AAOUJ} 15,3

\section{2}

institutions especially those who are job holders, some financial problems and women who have some family problems and above one million people are benefitting from AIOU in Pakistan and world.

Originality/value - This study is original in this respect because the data has been collected from the participants, i.e. students and teachers of AIOU. And it has also great value because this is the first SWOT analysis which has been conducted in this university to examine the strengths, weaknesses, opportunities and threats facing AIOU at present time. This study can also become a base for the stakeholders', i.e. policymakers, administration and higher education depart. of Pakistan in developing strategies to improve and amend the distance learning system of Pakistan especially at higher level in AIOU.

Keywords Education, Higher education, SWOT analysis, Distance learning system, AIOU Pakistan

Paper type Research paper

\section{Introduction}

Human capital plays a great role in the development of a nation and country. It is a fact that human capital can be obtained through proper education only. Educated people are more productive citizens because they can use the capital and new technology more effectively. So the human capital is directly related to the growth and development of a nation (Bordoloi, 2018). Therefore, education, either basic or at higher level, plays an important role in the development of human capitals that raises the economic, social and political status of the country in the world. Higher education is a much better investment than any other alternative (Bruner, 2012).

Higher education includes all types of education and research after the secondary level provided by universities or other educational institutions. These institutions are recognized as institutions of higher education by the authorities of the country (World Declaration on Higher Education for the Twenty-First Century: Vision and Action, 1998). The developing countries like Pakistan that is socially, economically and culturally diverse country, higher education institutions and universities, providing education and conducting research, are the basis that can elevate the economic and social status of the country (Husain and Malik, 2014).

But in Pakistan, like all the developing countries, the situation of higher education is not encouraging. Lack of good management, lack of budget and investment in research and development are the causes of poor higher education in Pakistan. According to Pakistan Education Statistics 2016-17, there are total 185 universities in both public and private sectors of education. According to QS World University rankings 2019, there was no Pakistani university at the top and only seven Pakistani universities are included among the top 1,000 universities. Pakistani universities are on the following numbers:

Table 1 gives information about the ranking of Pakistani universities in the world. It tells that Pakistan institute of engineering and applied sciences university was on 397 number, National university of sciences and technology on 447 number, Quaid-e-Azam university Islamabad on 551-560 number, Lahore university of management sciences on 701-750 number, COMSATS institute of information technology on 751-800 number, university of engineering and technology Lahore on 801-1000 number and university of Punjab on 8011000 number in the ranking of universities in the world. This table also gives information that there was included no distance university of Pakistan in this ranking.

\begin{tabular}{llc}
\hline Sr. No & Name of university & Rank \\
\hline 1 & Pakistan institute of engineering and applied sciences & 397 \\
2 & National university of sciences and technology (NUST) & 447 \\
3 & Quaid-e-Azam University Islamabad & $551-560$ \\
4 & Lahore university of management sciences (LUMS) & $701-750$ \\
5 & COMSATS Institute of information technology (CIIT) & $751-800$ \\
6 & University of engineering and technology Lahore (UET) & $801-1000$ \\
7 & University of Punjab & $801-1000$ \\
Source(s): https://www.topuniversities.com/university-rankings/world-university-rankings/2019
\end{tabular}

Source(s): https:/www.topuniversities.com/university-rankings/world-university-rankings/2019
Table 1.

Ranking of Pakistani universities as per QS world university ranking 
It is a fact that in Pakistan, the allocation of GDP on research and development in both public and private sector is very low and only $0.25 \%$ whereas the average allocation of GDP in developing countries like Korea and Japan is 4.23 and 3.28\% (Research and development expenditure \% of GDP- country Ranking, 2014). But in Pakistan, the expenditure on research and development is very low that is why, Pakistan has been ranked 109 among the 126 countries in the Global Innovative Index 2018 (Khan, 2018). In the entire world, there are two functions of universities, i.e. teaching and research. All the international ranking system in the world checks the performance of universities based on quality research products. But in Pakistan, educational institutions and universities are limited only toward the function of teaching and there is little attention to research work. The basic causes of this trend are lack of funds for research work, good policies and preferences of national planners.

It is the need of the hour that there should be clearly developed strategy and vision for the provision of higher education. The policies should be developed after examining the current needs of the institutions. A strategic plan stresses on whatever is necessary to help the institution to reach its vision and its purpose is to determine how resources will be allocated for a particular period (3, 5 or 10 years) to achieve the vision (Hinton, 2012). The main function of strategic planning is to understand the situation through SWOT analysis. SWOT analysis serves fundamental role in strategic planning that helps in scanning the institutional environment (Ahmad et al., 2017). Therefore, the study aimed to perform the SWOT analysis of higher education being provided by AIOU.

SWOT stands for strengths, weaknesses, opportunities and threats. SWOT analysis is a study of an institution's internal strengths and weaknesses, its opportunities for improvement and the threats the external environment presents to its survival (GretZky and Harrison, 2010). SWOT at first was developed for business but now is being used by all types of organizations and educational institutions.

So, SWOT is a broadly used instrument for exploring the internal factors, i.e. strengths and weaknesses and external factors, i.e. threats and opportunities of an institutional environment. In Pakistan, all the educational institutions and universities at higher level whether these are working in public or private or distance learning system are facing the same situation of SWOT. This study is conducted at higher level in public sector and distance learning system. Currently, there are two universities in Pakistan which are working through distance learning system, i.e. AIOU and Virtual university in Pakistan, whereas Higher Education Commission is working for the development of Open Distance Learning policy for the provision of higher education in all three modes like face to face, distance learning/e-learning and blended learning.

The present study was conducted at higher level provided by AIOU, being first distance learning university in Pakistan and Asia and the second in the world. Currently having 1.3 million enrollment, students are enrolled not only from Pakistan but also from the Middle East. The university is providing education to those who cannot study through formal education system because of poverty and job especially women who are job holders and having other responsibilities of the family. The study is beneficial for higher education sector in exploring the SWOT related to distance learning system at higher level in AIOU. The results may be utilized by higher education authorities in decision-making and planning at higher level in distance learning system especially in AIOU.

The objective of the study was to identify the SWOT in the provision of higher education by Allama Iqbal Open University Islamabad at MPhil and PhD levels.

\section{Review of related literature}

\subsection{Higher education}

Higher education plays an important role in the economic and social development of the country, also its role cannot be denied in human capital development. According to Kromydas
A SWOT analysis of AIOU

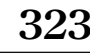


AAOUJ 15,3

(2017), educated individuals take part in a better way in the socio-economic development of the country. Higher education not only is helpful in the socio-economic development of the individuals and country but at the same time it has also a lot of advantages for human life and development. Higher education provides greater career opportunities, improves quality of life, provision of high social status, development in knowledge and wisdom, reduction in unemployment (Bruner, 2012). Therefore, there is a dire need to promote higher education in developing countries and especially in Pakistan. AIOU has a great potential to promote higher education in the country, at present many programs are being offered at MPhil and $\mathrm{PhD}$ levels but there is a need to perform analysis and inform policymakers for future improvements.

\subsection{Higher education in Pakistan}

The situation of higher education is not satisfactory in developing countries and especially in Pakistan. Only $4 \%$ of people are availing the opportunity of higher education in Pakistan, while in India and China it is 11 and $20 \%$ respectively.

Pakistan cannot compete with the progressive countries in all fields' especially in higher education and its higher education system is not considered strong in the world. A British Ranking Agency, Quacquarelli Symonds, in 2018 compared the strong higher education system of 50 countries in the world. In this ranking, Pakistan was on 50 as compared to India which was ranked 26 . This report declared the higher education system of Pakistan was weak in the world, whereas the top countries were United States and United Kingdom (QS higher education system strengths ranking, 2018). The ranking systems are based on system strength, access, performance and economic context. We may not compete with developed countries in the higher education system because of above criteria as our focus is teaching at higher education rather than research contributions and another reason may be research culture. In Pakistan, access to higher education is low only $4 \%$ and financial investment is $0.2 \%$. Most of the research carried out in Pakistan is academic and theoretical and it does not work for the welfare of the society. Its standard of quality is not at the international level. Mismanagement from the Govt. and lack of investment in research and development are responsible to a great extent the dismal situation of higher education in Pakistan (Khan, 2017). Because of all this, Pakistan's higher education system has been placed at the lowest level in the world.

For the development and progress of any country, the quality of higher education is the basic element (HEC, 2014). To strengthen the quality of higher education in Pakistan, the govt. should evaluate the current situations of higher education institutions. Each institution has some strengths and at the same time, it has also some weaknesses. Each institution has also some opportunities and it is also facing some threats. For this purpose the SWOT analysis is necessary.

\subsection{SWOT analysis}

A SWOT analysis for schools, colleges and universities is a tool that guides the governors, management teachers and staff, who are taking part in this analysis, and tells them what is effective and less effective in the system of the educational environment. In fact, a SWOT is used for any planning activity which can affect the future finance, planning and management decisions of the educational institutions (Morrison, 2018). SWOT analysis is used with strategic planning and it is considered as one of the success factors in a strategic planning process (Tolba, 2015). The strategic planning process is considered to be a powerful tool and guideline for helping all levels of higher educational institutions to develop their strategic plan and to find their competitive advantage and place within their environment (Shu-Hsiang and Ana, 2015). 
Thus, to achieve first position in the ranking and to compete with the progressive countries in the field of higher education, the higher education institutions have to expand their vision, mission, goals, objectives and strategies beyond the current practices to fulfill new functions to assure sustainable development in education (Chen Shu- Hsiang et al., 2015). It is possible only that the present situation of higher education institutions should be seen through SWOT analysis. The present study was also a SWOT analysis at a higher education institution and it was conducted in Pakistan.

\subsection{Distance learning system}

Distance learning system is that in which the learning occurs through correspondence study materials, tutorials, assignments, workshops, seminars and conferences. In Pakistan, there are two universities providing education through distance/virtual mode of learning, i.e. AIOU and Virtual University. The present study was conducted in AIOU and it was a SWOT analysis.

\subsection{Technical education in India: a SWOT analysis}

Singh and Solanki (2017) analyzed the SWOT in technical education in India. Data was narrative in nature and it was collected through different reports and views of the people. Conclusion was given that if India has to compete with the world, then Indian govt. should redesign all the institutions and policies related to technical education in India.

\subsection{SWOT of university of Maryland}

This research/SWOT analysis was conducted at the University of Maryland (UMD). It is a public research university in United States. This research work was done by Dennis in 2011. The methodology of this research work was quantitative in nature. The population of the study was students of the UMD and these were both male and female. The questionnaire was developed on a Likert-type scale. The results were also prepared by using statistical method, i.e. average. This SWOT analysis proved useful for developing strategies regarding SWOT in UMD.

\subsection{SWOT of Punjab university}

SWOT analysis was conducted in Punjab University (Pakistan) in 2016 by Husain, Ahmad, and Khalil. Punjab University is a public sector university providing education using formal system. A survey was done to identify the SWOT in the university. For this purpose, a questionnaire was used to get the students' responses. This research was quantitative in nature. The results indicated that there was no significant difference in the male and female opinions regarding SWOT in the university.

\subsection{Queensland government-conducting a SWOT analysis}

Queensland Government website has described that there are eight steps to conduct a SWOT analysis:

(1) The objective of SWOT analysis

(2) Understanding/research about the concerned work

(3) Make a list of research strengths

(4) Make a list of research weaknesses

(5) Make a list of research opportunities

(6) Make a list of research threats 

AAOUJ
(7) Make a list of priorities from the SWOT
15,3
(8) To make a strategy to overcome these issues

The present research work was also SWOT analysis conducted by utilizing above steps. So for this purpose a questionnaire and interview schedule was developed to get information. The most valid and relevant sources were the students and teachers therefore were included in population of the study. The researchers have identified the SWOT.

\section{Methodology}

The present study was a SWOT analysis and it used mixed-method research in which both the quantitative and qualitative methods were used. The objective of the study was to identify the SWOT in higher education - SWOT analysis of AIOU. To achieve this objective, survey and interview techniques were used. The data of questionnaire was quantitative in nature and data of interview was narrative form. A good SWOT analysis also requires that both types of techniques, i.e. quantitative and qualitative should be used.

\subsection{Population}

The population of the study was all the students of MPhil and $\mathrm{PhD}$ levels at AIOU and the teachers of these students working at higher level in AIOU. So all the research students of the previous five years and teachers at MPhil and PhD levels were the population of the study.

\subsection{Sampling technique}

The population of the study was divided in two strata, i.e. students and teachers. There are four faculties in university, departments offering MPhil and $\mathrm{PhD}$ were selected at first stage, list of students completed MPhil and $\mathrm{PhD}$ from the departments along with their supervisors were collected. 100 students and 10 teachers from each faculty were randomly selected as sample of study. Overall 400 students and 40 teachers were sampled, whereas 370 students responded the survey and all 40 teachers were interviewed but there was variation in the quality of responses, and some of the teachers were not having enough time for interview. So interview data of 37 respondents was analyzed.

\subsection{Instruments of the study}

The researchers developed instruments according to the demand of the study, i.e. it was developed according to the distance education system in AIOU. The questionnaire consisted of two parts. The first part consisted of demographic information (faculty, department and number). Likert-type scale was used to determine the respondents view points as strongly agree (4), agree (3), uncertain (2), disagree (1) and strongly disagree (0) regarding SWOT for programs offered by AIOU. An interview was conducted with the faculty members/teachers to know about the SWOT in higher education programs offered by AIOU.

\subsection{Validation of the instruments}

The instruments were validated by five experts in the field of distance education. The necessary changes were made based on the suggestions of the experts. Final tools were administered for data collection.

\subsection{Reliability of the instruments}

For the reliability, questionnaire was pilot tested on a sample of 20 students, not included in the sample of the study. The coefficient alpha for consistency of the statements of the 
questionnaire was 0.85 . The pilot interviews of two faculty members were conducted to ensure the suitability and consumption of time for the interview. Interview questions were rephrased accordingly.

\subsection{Analysis of data}

Data of the questionnaire was analyzed by using a statistical method, i.e. mean and standard deviation and data of interview was in narrative form and it was analyzed by the researchers by using thematic analysis technique.

\subsection{Results}

There were 400 students selected as a sample of study. But the 30 students did not respond to the questionnaire. So results of the study were drawn from 370 responses of the students. The analysis of the students' data is as follows.

3.7.1 Analysis of questionnaire data. Table 2 presents the analysis of the data on the responses of strengths of AIOU as perceived by the students of MPhil and $\mathrm{PhD}$ programs.

Table 2 shows that statements regarding provision of learning environment, competence of the faculty in supervision of research and physical facilities for learning at main campus are rated high by the research students at higher education level. So these may be considered as strengths of AIOU. The mean score of the other statements also shows that the students agreed means that AIOU has strengths regarding competent workers, variety of disciplines and positive interaction.

There were 11 statements to assess the weaknesses of AIOU in the views of research students at higher education level. The analyses of the responses are summarized below.

Table 3 tells about the weaknesses of AIOU. Most of the students highlighted that fewer times from faculty members due to workload, slow research process, nonexistence of an academic advisory body and slow communication as major weaknesses in the conduct of research at higher education level. AIOU also needs to improve the areas like provision of scholarships for students and faculty, the stress of faculty on teachers, not provision of necessary services by AIOU, shortage of funds and their improper use and strict process of

\begin{tabular}{|c|c|c|c|}
\hline Statements & Mean & $\mathrm{SD}$ & \\
\hline $\begin{array}{l}\text { AIOU provides education to those who are job holders/family/financial problems and } \\
\text { especially women who cannot study regularly to enhance their qualification and professional } \\
\text { skills }\end{array}$ & 2.79 & 1.15 & \\
\hline $\begin{array}{l}\text { AIOU provides curricular and co-curricular activities through corresponding study materials, } \\
\text { tutorials, workshops, assignments, conferences, seminars and laboratories }\end{array}$ & 2.80 & 1.15 & \\
\hline AIOU main campus have safe and good environment for learning & 2.79 & 1.15 & \\
\hline $\begin{array}{l}\text { AIOU is the biggest university in Asia in the distance system and it has a positive reputation in } \\
\text { the world as well as in the external community }\end{array}$ & 2.81 & 1.15 & \\
\hline $\begin{array}{l}\text { AIOU main campus has the facility of new, well-maintained, attractive buildings, vast beautiful } \\
\text { grounds and regional campuses have also the facility of new and well-maintained buildings }\end{array}$ & 3.10 & 1.40 & \\
\hline AIOU has competent workers and faculty members, especially at MPhil and PhD levels & 3.12 & 1.37 & \\
\hline AIOU has good teaching and learning environment & 3.30 & 1.36 & \\
\hline AIOU provides research-based learning environment & 3.10 & 0.76 & Table 2. \\
\hline AIOU supervisors are competent and expert in the field of research & 3.22 & 0.67 & Internal characteristics \\
\hline AIOU research practice varies across disciplines & 2.90 & 1.36 & of AIOU as strengths in \\
\hline $\begin{array}{l}\text { AIOU faculty members have strong interaction between faculty members for research } \\
\text { guidance and supervision }\end{array}$ & 2.93 & 1.53 & $\begin{array}{r}\text { views of research } \\
\text { students }\end{array}$ \\
\hline
\end{tabular}


AAOUJ 15,3
Statements

AIOU lacks good administration, check and balance

AIOU does not provide study material to students and workshop schedule information in time especially to those who live in remote areas where there is not the facility of Internet

Most of the students miss their workshop, assignment and papers because of work and family commitments

AIOU resource persons do not satisfy the students during workshops

Most of the students cannot contact with their tutors directly

AIOU supervisors take limited number of students and do not guide the other students

AIOU has no academic advising council that help students in tool development process

AIOU lacks in provision of scholarships to faculty members and students

Stress of workload like attend meetings and seminars etc. limit their time to spend with research students

Table 3.

Internal characteristic of AIOU as weaknesses in views of students
AIOU has slow research process

AIOU has strict process of issuing degrees and result cards

AIOU has less research funds and facilities for faculty and staff
Mean SD

$3.10 \quad 0.99$

$3.08 \quad 0.97$

$3.07 \quad 1.15$

$2.81 \quad 1.15$

$3.10 \quad 1.40$

$2.85 \quad 1.37$

$3.30 \quad 1.36$

$3.00 \quad 1.13$

$3.30 \quad 1.22$

$3.30 \quad 1.36$

$2.25 \quad 1.08$

$2.83 \quad 0.53$

issuing degrees and result cards and different no objections and approvals for the conduct of research.

There were 10 statements to assess the conditions or situations that are considered to have positive impact in creating a conducive teaching learning environment and opportunities in the conduct of research. The summary of the responses is presented below.

Table 4 describes that AIOU students consider natural conducive environment, beautiful location and comprehensive MPhil and $\mathrm{PhD}$ enrollment process as opportunities. It also highlights that use of instructional media and technologies, delivery of instructions through multimedia, having equipped study centers, science laboratories and access to library recourses are great opportunities to learners interested in conduct of research.

There were nine statements to assess the level of external threats to AIOU. The responses of the research students regarding threats are elicited in the table below.

Table 5 shows most of the students were agreed that AIOU has threats related to lack of financial support, delay in research process, lack of public support and attitude, not good management system, more competitors and increasing fee structures. Another threat about which the majority of the students were agreed was employing formal education rules for distance learners.

3.7.2 Analysis of interview data for faculty members/teachers. Interviews were conducted to elicit the faculty views regarding SWOT to AIOU higher education programs. Initially it was planned to conduct 40 interviews, but three faculty members were not available at day of interview due to their engagement in official or personal commitments. Also few other interviews were very short in nature and almost agreed to our point of view. Many of the faculty members took good interest and provided their insight that helped researchers to align quantitative data with qualitative input. Most of the teachers were performing many responsibilities, i.e. to attend meetings, seminars, conferences and to conduct workshops. In addition, they also have to give time to their research students. Most of the teachers stated that they have not been given enough opportunity to go abroad for further studies or to attend conferences/seminars and their salary package is not high that they may manage of their own. Majority of the teachers told that their research students belong to remote areas of Pakistan and they have less time for their studies especially about research work because of financial/family/ job problems. These students continue their research work after short breaks of time. In this way, there is delay in the research process. Every faculty member has only four or five students and HEC allows them to take maximum eight students. When these students become late, there 
Statements

Location and physical environment of AIOU main campus is suitable for learning

AIOU follow comprehensive criteria for enrolment of students at MPhil and PhD levels

AIOU is also providing full-time study centers for some of the masters levels programs that are well equipped and conducive for learning

Instructional media and technologies used for higher education are new and meet the global standards

Technology usage is helpful for students in conduct of research and locating the recent resources

AIOU library is well equipped and meets the needs of the learners

Comprehensive and systematic rules for academic progression of the learners help to improve the efficiency of the university

Well-equipped laboratories are available at AIOU for science students and researchers in its science complex

Departments offering programs at higher education level invites foreign speakers to deliver lecturers during workshops

AIOU environment motivates learner to conduct research

M

Mean

$\mathrm{SD}$

$3.00 \quad 1.30$

$3.07 \quad 0.87$

$3.07 \quad 1.85$

$2.83 \quad 1.47$

3.35 $3.30 \quad 1.22$

$2.27 \quad 1.75$

3.36

0.95

3.35

1.13

2.80

0.88
A SWOT analysis of AIOU 75

Table 4.

Internal conditions that have a positive impact on AIOU system as perceived by research students

\begin{tabular}{|c|c|c|c|}
\hline Statements & Mean & SD & \\
\hline Less provision of resource by the Government & 3.10 & 0.99 & \\
\hline Increase in fees and strict criteria for admission & 3.12 & 1.12 & \\
\hline Other universities and institutions switching to open distance learning & 3.12 & 1.12 & \\
\hline Employees satisfaction level and their commitment & 2.87 & 1.37 & \\
\hline Conduct of classes during working days for students who are already employed & 3.35 & 0.88 & \\
\hline Attitude of general public toward open distance learning & 2.87 & 1.35 & \\
\hline Following the rules of formal system for distance learners & 3.05 & 0.78 & Table 5. \\
\hline Lack of comprehensive students support system & 3.32 & 1.75 & External conditions as \\
\hline Need to visit main campus for solution of managerial problems & 3.35 & 1.13 & threats to AIOU \\
\hline
\end{tabular}

is no space for the new comers and these new students have to go other universities/ supervisors. In this way, these students face a lot of difficulties and get their degrees late.

Most of the teachers were of the view that students do not attend their workshops and submit assignments in time. In this way, they spend many years in one program and their thesis that delays their degree. They stated that like the formal universities, AIOU sends thesis/research work to other universities for external evaluation. This process also takes many months, i.e. at least six months or above and it also slows the research work. Majority of the teachers who were the coordinators of the courses told there is less time, i.e. only five or six days to complete the course work while conducting workshop of the course.

Most of the faculty members demanded that the AIOU should provide them more opportunities for professional development. In this way, they will learn new methods of teaching and learning. AIOU should also increase the number of faculty members and their qualifications as well. There is also a great stress on the faculty of workload and other responsibilities that consume most of their time. Faculty members agreed that increasing fees and mushroom growth of distance learning institutions without maintaining the standards are capturing students and are threats to AIOU. They also viewed that there should be separate rules for distance learners; credit calculation should include the weight and age for self-study. And the workload of the faculty members should be calculated by considering their effort on unit writing and course development and their salary package is also not high. HEC of Pakistan 
AAOUJ 15,3

should also allow developing new rules/policies for the regulation of open distance learning in Pakistan. They viewed that the faculty of AIOU is skilled and experienced, their skill and experience may be utilized for the professional development of other institutions.

\section{Discussion}

The present study aimed to conduct SWOT analysis of higher education programs offered by AIOU, Pakistan. This study found that like all the formal and distance universities of Pakistan and world, AIOU has also SWOT regarding distance education system. But if the Government policymakers and HEC adopts such strategies in the light of the SWOT, AIOU has potential to become a leading distance university at all levels especially at MPhil and $\mathrm{PhD}$ levels. It was found that AIOU has comprehensive rules for regulating open distance learning across the country. The students face communication problems but Internet and social media usage have made it easier for many of the learners. Some students living in remote areas, not having Internet facilities miss admission schedules, their workshops, assignments and examination. This creates a problem and their duration of studies become lengthy and cause a delay in the research process.

But at the same time, it is also a fact that the majority of learners are jobholders and have family commitments as well, especially female students living in remote areas having financial problems are getting educational benefits from AIOU.

Although time and space are flexible for learning, the strict admission criteria is a barrier for students living in remote areas. There is a need to expand the programs of higher education across the country by increasing the number of admissions each semester.

The important aspect to consider is that most of the learners think that delay in their research work is due to their supervisor as he/she is not having enough time for the students. But on the other hand, faculty think that students delay their work due to other commitments, like family and job. AIOU can make this situation better, as most of the faculty members of AIOU are competent and expert in research work.

One of the most common complaints of the research students is that supervisors do not conduct frequent meetings due to busy schedules of department or teaching responsibilities, more numbers of students under their supervision or out of university because of some faculty/university work (Spear, 2000). So it is the duty of the policymakers/educational leaders to give/provide higher education according to students' needs that will help in the development of educated people with a progressive, logical and skillful mind (Bordoli, 2018).

AIOU library has good Internet system and it has provided many books in all disciplines and purchased many research articles for the students' needs at MPhil and $\mathrm{PhD}$ levels. The hostel facility is also good in AIOU. So these are considered as opportunities to learners and strengths of AIOU, learning environment. Fee enhancement is a threat to enrollment as at higher education level conduct of research is costly and students are facing problems, therefore enhancement in fee and other charges created difficulty for research students. If fee and charges will be the same as that of formal institutions, students may prefer formal institutes instead of open distance mode of learning. We should think to reduce the cost of learning and provide maximum flexibility to the learners, without compromising the quality of programs.

It is the need of the hour that the government, policymakers and HEC should adopt such strategies in the light of the present SWOT. Careful consideration of factors identified in this research AIOU can become a leading distance university at all levels.

\section{Conclusions}

The important aim of Open and Distance institution is to provide an opportunity to students for study by overcoming the geographical, race, gender, age differences, socio-economic and other boundaries/restrictions. As Jeong (2018) has also stated that open universities all over the world are based on open and distance educational institutions and follow this particular objective. AIOU is also playing its role in respect of distance learning system and is following 
this objective. This study was about AIOU (a distance university in Pakistan) and the research was conducted at higher level. Higher education is important because it plays a great role in the development of individuals and the country. Higher education should be of such type that it should play a great role in the development of human resources by raising the number of educated population that will take part in the socio-economic mobility, peace and development in society (Bordoli, 2018).

This study highlighted that AIOU has beautiful, attractive buildings and especially main campus, a good system of delivery of books and assignments and paper schedule. But the great concern is at higher education level. The criteria for admissions at this level are strict but the research work creates a lot of trouble for students at this level. The students feel a great difficulty even many months in approving the topic of their research work and in the selection of supervisors. AIOU supervisors are competent and efficient but they have less time for their research students because of other responsibilities, i.e. meetings, conferences, seminars and workshops. Spear states that supervisors should read the students written work completely and suggest some critical points on his/her written work. It plays an important role in the intellectual development of students (Spear, 2000)' most of the AIOU faculty is doing this and guiding students appropriately.

In the distance learning system, fee charges should not be such or like the other formal universities as the people could not afford them and some scholarships/financial aid should be given to needy/bright students. Every institution formal/private/distance indeed has SWOT; AIOU is also not free from this situation. The special aim of the AIOU is to provide quality higher education to Pakistani peoples living in rural and isolated parts of the country (Ally and Khan, 2015). Therefore, AIOU authorities/policymakers should act according to this aim/objective and make such changes/steps that all levels of education especially the higher level should be perfect and according to students' needs and abilities.

In AIOU, there is also a strict process of issuing result cards and degrees at higher level. A student can get his/her PC, if she/he has all the original degrees. Unfortunately, if any student has not one original degree, he/she will not be able to get his/her result card. In this difficult process, he/she can miss admission in $\mathrm{PhD}$, special allowance from the Government (If he/she is job holder) and cannot get opportunity of applying jobs at higher level. So the researchers demand that the degree section of AIOU system should make some flexible rules of issuing result cards at higher level, i.e. the AIOU should verify itself own the students other degrees from the other universities and the students should be responsible for paying its fee or should take such steps that the students could get their result cards and degrees in time.

The Government, the policymakers and the administrative officers of AIOU should adopt careful strategic planning/policies/decisions at higher level according to institution/students' needs and especially should take special measures to strengthen the research culture. In this way, AIOU can also become a leading distance university at all levels especially at higher level not only in Pakistan but also in the whole world. The doors of education will be opened for all which is the slogan of AIOU "Education for All" and those individuals will also be prepared who can take part in the process of progress and development of the country. The researchers considered that it should not be the destiny of the AIOU students that they have to remain behind not only from the students of other formal universities of Pakistan but also in the world.

\section{Recommendations}

The researchers recommend the following.

(1) AIOU should make better corresponding system by sending study materials in time and informing them about assignment, workshops and exam schedules.

(2) AIOU should reconsider fee package at all levels especially at MPhil and $\mathrm{PhD}$ levels and the charges should bring at moderate level.
A SWOT analysis of AIOU 
AAOUJ 15,3

\section{2}

(3) AIOU should increase the number of faculty members and their qualification should be at least $\mathrm{PhD}$. Faculty professional development programs may be initiated to enhance the skill and competence of faculty.

(4) AIOU may bind research scholars that they should select their supervisors from their own department.

(5) AIOU may adopt such a strategy that the research work of students should not be late, i.e. in guidance of the selection of research topics and supervisors.

(6) AIOU should make such a system that the necessary information about AIOU system could reach every individual well in time. Student support services may be vibrant to address all issues of distance learners.

(7) HEC in Pakistan should make such policies in all the formal universities and especially in the AIOU that time for external evaluation of research work may not exceed more than three months.

(8) AIOU may develop such strategies that the problems that coordinators face during conducting the workshops should be minimized.

(9) AIOU authorities may appoint an advisor from the faculty members that his/her contact should be with the students to solve their problems especially about the research work, i.e. in the selection of research topic and supervisor and also help them with the assignment and workshop schedule.

(10) AIOU degree section/examination department should adopt some flexible rules in issuing degrees and result cards to reduce the students' problems.

\section{References}

Ahmad, S., Husain, A., Khalil, A. and Misbah, M. (2017), "A SWOT analysis on institutional environments of university of the Punjab", International Journal of Humanities and Social Sciences, Vol. 11 No. 4, pp. 62-66.

Ally, M. and Khan, B. (2015), International Handbook of E-Learning Volume 2.. . Implementation and Case Studies, 1st ed., Kindle ed., Rutledge international handbook of Education.

Bordoloi, R. (2018), "Transforming and empowering higher education through open and distance learning in India", Asian Association of Open Universities Journal, Vol. 13 No. 1, pp. 24-36.

Bruner, B. (2012), "The role on one's own higher education", Management Education, Rankings. UVADARDEN. available at: https://blogs.darden.virginia.edu/brunerblog/2012/10/the-role-on-onesown-higher-education/.

GretZky, W. and Harrison, J.P. (2010), Strategic Planning and SWOT Analysis, Chapter 1, Health Administration Press, p. 91.

Hinton, K.E. (2012), A Practical Guide to Strategic Planning in Higher Education, Society for College and University Planning (Integrated Plans for Higher Education), ISBN 978-1-9937724-13-9, p. 50.

Husain, E. and Malik, A.A. (2014), "Role of universities in the development of Pakistan", Daily Times, available at: https://dailytimes.com.pk/102856/role-of-universities-in-the-development-of-pakisan.

Jeong, H. (2018), "Rethinking the rationale of open and distance education: a case of the UK open university", Asian Association of open Universities Journal, Vol. 13 No. 2, pp. 169-179.

Khan, T. (2017), "The sad dilemma of higher education and research in Pakistan", available at: blogs. Dunyanews.tv/17430/.

Khan, A. (2018), “Global innovative Index revealed”, Daily Times, available at: https://dailytimes.com. pk/293504/global-innovation-index-2018-revealed/. 
Kromydas, T. (2017), "Rethinking higher education and its relationship with social inequalities: past knowledge, present state and future potential", Palgrave Commun, Vol. 3 No. 1, doi: 10.1057/s41599-017-0001-8.

Morrison, M. (2018), SWOT Analysis for Schools/Education/Colleges/Universities, RAPID BI (knowledge, understanding and action), available at: https://rapidbi.com/swot-analysis-for-schools-and-education.

QS Higher Education System Strengths Rankings (2018), available at: https://www.topuniversities. com/system-strength-rankings/2018.

Ranking (2014), Ranking of Pakistani Higher Education Institutions, available at: hec.gov.pk/ englishservices/universities/ranking/2014/Documents/2014\%20doc.

Shu-Hsiang, C., Jaitip, N. and Ana, D. (2015), "From vision to action- strategic planning process model for open educational resources", Procedia-Social and Behavioral Sciences, Vol. 174, pp. 3707-3714.

Singh, Y. and Solanki, M. (2017), "Technical education in India: a SWOT analysis", Journal for Social Research, Vol. 13 No. 12.

Spear, R.H. (2000), Supervision of Research Students: Responding to Students Expectations, The Australian National University, Canberra.

Tolba, S., A. (2015), "SWOT analysis-A great strategic planning tool", Strategic Plan Process, available at: https://www.Linkedin.com/pulse/swot-analysis-great-strategic= planning-tool-ahmad-samir-tolba.

World Declaration on Higher Education for the Twenty-First Century: Vision and Action (1998), World Conference on Higher Education, UNESCO, Paris.

\section{Corresponding author}

Khalida Nasreen can be contacted at: nasreengul78@gmail.com
A SWOT analysis of AIOU 